\title{
In vitro study of the role of thrombin in platelet rich plasma (PRP) preparation: utility for gel formation and impact in growth factors release
}

\author{
Huber SC ${ }^{1}$, Cunha JL ${ }^{1}$, Montalvão SAL ${ }^{1}$, da Silva LQ ${ }^{1}$, Paffaro AU ${ }^{1}$, da Silva FAR ${ }^{1}$, Rodrigues BL ${ }^{1}$, Lana JFSD ${ }^{1}$, Annichino-Bizzacchi JM $^{1}$
}

Introduction: The use of PRP has been studied for different fields, with promising results in regenerative medicine. Until now, there is no study in the literature evaluating thrombin levels in serum, used as autologous thrombin preparation. Therefore, in the present study we evaluated the role played by different thrombin concentrations in PRP and the impact in the release of growth factors. Also, different activators for PRP gel formation were evaluated. Methods: Thrombin levels were measured in different autologous preparations: serum, L-PRP (PRP rich in leukocytes) and T-PRP (thrombin produced through PRP added calcium gluconate). L-PRP was prepared according to the literature, with platelets and leukocytes being quantified. The effect of autologous thrombin associated or not with calcium in PRP gel was determined by measuring the time of gel formation. The relationship between thrombin concentration and release of growth factors was determined by growth factors (PDGF-AA, VEGF and EGF) multiplex analysis. Results: A similar concentration of thrombin was observed in serum, L-PRP and TPRP (8.13 nM, $8.63 \mathrm{nM}$ and $7.56 \mathrm{nM}$, respectively) with a high variation between individuals (CV\%: $35.07,43$ and 58.42 , respectively). T-PRP and serum with calcium chloride showed similar results in time to promote gel formation. The increase of thrombin concentrations (2.66, 8 and $24 \mathrm{nM}$ ) did not promote an increase in growth factor release. Conclusions: The technique of using serum as a thrombin source proved to be the most efficient and reproducible for promoting PRP gel formation, with some advantages when compared to other activation methods, as this technique is easier and quicker with no need of consuming part of PRP. Noteworthy, PRP activation using different thrombin concentrations did not promote a higher release of growth factors, appearing not to be necessary when PRP is used as a suspension.

Key Words: Platelet Rich Plasma, Thrombin, gel, Leukocytes, Growth factor

\section{Introduction}

Platelet rich plasma (PRP) is defined as a concentrate preparation that increases between 4 to 9 folds the basal number of platelets, in reduced plasma volume ${ }^{[1]}$. Platelets contain over 1100 proteins including growth factors, messengers of the immune system, enzymes, enzyme inhibitors and other bioactive compounds. These factors can improve tissue repair by diverse mechanisms including regulation of inflammation, angiogenesis, synthesis and remodeling of new tissues ${ }^{[2,3]}$. For these reasons, PRP has been used in different fields: odontology ${ }^{[4]}$, plastic surgery $^{[5]}$, orthopedics ${ }^{[6]}$, wound healing ${ }^{[7]}$ and aesthetics ${ }^{[8]}$ with promising results. However, biomolecules are known to be quickly released from PRP, losing their activity in a short period of time which could represent a challenge in clinical practice ${ }^{[9]}$.

PRP preparations have been used since 1970s, however they become popular in 1990s. Since then, different protocols emerged to prepare PRP including commercial systems ${ }^{[10]}$. Despite the promising results published by different research groups, the heterogeneity of protocols for PRP preparation available, render the evaluation of a consistent therapeutic effect quite difficult. In vitro studies evidenced that the different methodologies used in the preparation of PRP can affect biological aspects and clinical effects, which depend on several variables, particularly platelet and growth factor concentration, presence or absence of leukocytes and the type of activation ${ }^{[2]}$.
PRP is usually prepared by double centrifugation of anticoagulated blood. The first spin is to separate red blood cells and plasma; the second spin is to concentrate platelets. Despite the existing PRP standardization proposals, there is no consensus regarding centrifugation force or duration. This absence of a standard PRP preparation inhibits any comparisons of treatment efficacy obtained by different research groups. The inclusion or not of leukocytes is also widely discussed in the literature. PRP with leukocytes (L-PRP) presents different biologic activity, which could modify the therapeutic effect ${ }^{[11]}$.

Another important issue is the activation for growth factor release. This activation can be induced by bovine or autologous thrombin, calcium chloride, collagen, freeze \& thaw cycles and mechanical trauma. Collagen and thrombin activate platelets by different mechanisms. For the activation of platelets by collagen, they must first adhere to collagen and then became active by it through a second receptor. This kind of platelet activation may require a lengthier mechanism than the cleavage process of thrombin-mediated platelet activation ${ }^{[12]}$. Park and collaborators demonstrated that thrombin is a strong agonist for induction of PRP cytokines and growth factors release when compared to ADP + calcium or collagen ${ }^{[13]}$. Once PRP activation is achieved, a fibrin network begins to form with a rapid growth factor release during the first hour, continuing to release cytokines and growth factors from their mRNA for at least another 7 days $^{[14,15]}$.

Author Names in full: Stephany Cares Huber ${ }^{1}$, José Luiz Rosenberis Cunha Júnior ${ }^{1}$, Silmara Montalvãoํㅡㄹ Letícia Queiroz da Silva ${ }^{1}$, Aline Urban

Paffaro $^{1}$, Francesca Aparecida Ramos da Silva ${ }^{1}$, Bruno Lima Rodrigues ${ }^{1}$, José Fabio Santos Duarte Lana ${ }^{1}$, Joyce Maria Annichinno-Bizzacchi ${ }^{1}$

${ }^{1}$ Hemocentro, Haemostasis Laboratory, State University of Campinas UNICAMP, Brazil. 
There is no consensus in the literature regarding the choice of the best activator and whether PRP should be used with or without activation in clinical practice. The most common activation method included a single amount of thrombin in association with calcium chloride. However, different sources and procedures to obtain thrombin can also interfere with the PRP therapeutic effect. Bovine thrombin may present adverse reactions including hemorrhage, thrombosis, and immune reaction, thus, autologous thrombin has been preferred to avoid this clinical complication. Autologous thrombin can be obtained from serum samples or by using calcium gluconate to clot PRP (T$\mathrm{PRP})^{[16]}$. In this context, autologous serum, which is simple to obtain, could represent a promising source of thrombin, however this source has not been investigated in practice. Therefore, the impact of thrombin and other PRP activators should be investigated, which led us in the present study to evaluate the role of thrombin in PRP preparations in terms of time for gel formation and of growth factor release.

\section{Material and Methods}

\section{Subjects}

Forty-two healthy individuals (30 female: 12 male), with mean age of 32.5 years and SD \pm 9.36 were included. None of the donators had taken any medication that could interfere with hematological parameters. The local Ethic Committee approved data collection and all procedures were in accordance with the ethical standards and with the Helsinki Declaration.

\section{Autologous preparations}

\section{Preparation of $L-P R P$}

For each volunteer, peripheral blood was collected by venous puncture in eight vacuum tubes: six $8.5 \mathrm{ml}$ ACD tubes, one EDTA and one tube without anticoagulant (BD Vacutainer). L-PRP preparation was performed according to Amable's methodology ${ }^{[10]}$; the first spin at $300 \mathrm{~g}$ for 5 minutes and the second spin at $700 \mathrm{~g}$ for 17 minutes. The buffy-coat rich with leukocytes (L-PRP) was collected from all tubes. At the end of the double spin the top layer plasma was characterized as platelet poor plasma (PPP - 80\% volume) and the lower layer was the PRP (20\% volume). Platelet counts were carried out in whole blood and PRP samples with Siemens Advia120 and Advia2120i hematology analyzers.

\section{T-PRP}

T-PRP was prepared by a modified protocol described by Franco et al. ${ }^{[16]} ; 1.5 \mathrm{~mL}$ of L-PRP were mixed with $0.5 \mathrm{~mL}$ of $10 \%$ calcium gluconate, and incubated for 15 minutes in a $37{ }^{\circ} \mathrm{C}$ water bath. After L-PRP clotting, the tubes were centrifuged at $800 \mathrm{~g}$ for 10 minutes, and the supernatant was separated.

\section{Serum}

Serum was collected by venous puncture into a tube without anticoagulant and centrifuged at $1260 \mathrm{~g}$ for 10 minutes.

\section{Autologous thrombin assessment}

We determined thrombin concentration in L-PRP, T-PRP and serum. Thrombin concentration was measured through fluorogenic assay, conducted with an enzyme-specific fluorogenic substrate (FluCa Reagent, Thrombinoscope), and a standard curve of purified exogenous thrombin (Thrombin Calibrator, Thrombinoscope).

Thrombin generation test (TGT) with CAT Calibrated Automated Thrombogram (CAT) Thrombinoscope (Fluoroskan ascent Thermo) was performed in order to investigate the presence and the ability to generate thrombin of the thrombin precursor in the same samples.

\section{Assessment of PRP Gel Formation}

L-PRP gel formation was analyzed using thrombin preparations and/or calcium in $12 \times 75 \mathrm{~mm}$ polystyrene tubes (Table 1). Nine healthy volunteers were used to produce L-PRP, and the thrombin concentrations were evaluated by fluorogenic assay of T-PRP and serum of each sample. Activators were mixed with each L-PRP in a final reaction volume of $200 \mu \mathrm{L}$. The tubes were then incubated at room temperature, without agitation. The time required for gel formation was considered as the period between the addition of the activator and the beginning of fibrin formation, as an indirect measure of time for PRP gel formation. This protocol is standardized and broadly used for coagulation tests as described by Kitchen and collaborators, and Clinical and Laboratory Standards Institute (CLSI) guideline $\mathrm{e}^{[17,18]}$.

Table 1: Activators tested for gel formation

\begin{tabular}{|c|c|c|}
\hline Combination & Type of activator & Description \\
\hline 1 & T-PRP & $\begin{array}{l}\text { Thrombin produced from PRP with } \\
\text { Calcium Gluconate } 0.5 \%\end{array}$ \\
\hline 2 & Serum & $\begin{array}{l}\text { Thrombin produced with autologous } \\
\text { serum }\end{array}$ \\
\hline 3 & Serum $+0.5 \% \mathrm{CaCl}_{2}$ & $\begin{array}{l}\text { Thrombin produced with autologous } \\
\text { serum with } 0.5 \% \mathrm{CaCl}_{2}\end{array}$ \\
\hline 4 & $\begin{array}{l}\text { Serum + Calcium Gluconate } \\
\left(\mathrm{C}_{12} \mathrm{H}_{22} \mathrm{CaO}_{14}\right) 0.5 \%\end{array}$ & $\begin{array}{l}\text { Thrombin produced with autologous } \\
\text { serum with } 0.5 \% \mathrm{C}_{12} \mathrm{H}_{22} \mathrm{CaO} 14\end{array}$ \\
\hline 5 & Calcium Chloride $\left(\mathrm{CaCl}_{2}\right) 0.5 \%$ & Only with $0.5 \% \mathrm{CaCl}_{2}$ without thrombin \\
\hline 6 & Calcium Chloride $\left(\mathrm{CaCl}_{2}\right) 2.5 \%$ & Only with $2.5 \% \mathrm{CaCl}_{2}$ without thrombin \\
\hline 7 & $\begin{array}{l}\text { Calcium Gluconate } \\
\left(\mathrm{C}_{12} \mathrm{H}_{22} \mathrm{CaO} 14\right) 0.5 \%\end{array}$ & $\begin{array}{c}\text { Only with } 0.5 \% \mathrm{C}_{12} \mathrm{H}_{22} \mathrm{CaO} 14 \text { without } \\
\text { thrombin }\end{array}$ \\
\hline 8 & $\begin{array}{l}\text { Calcium Gluconate } \\
\left(\mathrm{C}_{12} \mathrm{H}_{22} \mathrm{CaO}_{14}\right) 2.5 \%\end{array}$ & $\begin{array}{c}\text { Only with } 2.5 \% \mathrm{C} 12 \mathrm{H} 22 \mathrm{CaO} 14 \text { without } \\
\text { thrombin }\end{array}$ \\
\hline
\end{tabular}

\section{Method to concentrate thrombin for analysis of growth factor release}

Growth factors released from L-PRP were evaluated using thrombin obtained from a modified methodology previously described by Saxena et al. ${ }^{[19]}$. Thrombin had a concentration of $121 \mathrm{nM}$, measured through fluorogenic assay, conducted with an enzyme-specific fluorogenic substrate (FluCa Reagent, Thrombinoscope), and a standard curve of purified exogenous thrombin (Thrombin Calibrator, Thrombinoscope). 
Quantitative measurement of growth factors released from L-PRP using different thrombin concentrations

The aim of this analysis was to verify whether different thrombin concentrations $(0,2.66,8$ and $24 \mathrm{nM})$ could interfere with the release of the growth factors. The growth factors evaluated were: platelet derived growth factor (PDGF-AA), epidermal growth factor (EGF) and vascular endothelial growth factor (VEGF) measured through multiplex analysis - Luminex (Milipore). To this end, L-PRP samples were normalized at a concentration of $1200 \times 10^{3}$ platelets $/ \mu 1$, diluted in PPP and activated with different thrombin concentrations as previously described. The activated samples were incubated in a water bath at $37^{\circ} \mathrm{C}$ for one hour. Posteriorly, it used two different protocols to evaluate the release of growth factors: 1) The samples were then treated with 3 cycles of nitrogen to dissolve the clot, as described by Matsui and Tabata ${ }^{[20]}$, and 2) The samples were centrifuged at $200 \mathrm{~g}$ for 5 minutes and the supernatant was used, as described in manufacturer procedures The protocols of Luminex were carried out following the manufacturer's instructions.

\section{Statistical analysis}

Variables were tested to verify the normality using the Shapiro-Wilk test. As the variables did not have a normal distribution, Friedman test with Dunn's post-test were used for all comparisons. Spearman's rank correlation coefficient test was used for the correlation tests. The GraphPad Prism 5.0 software was used and $\mathrm{p}<0.05$ was considered significant.

\section{Results}

\section{PRP characterization}

The methodology for PRP preparation was able to recover high concentrations of platelets (PLT) and white blood cells (WBC) as shown in Figure 1 (A and B). The figure evidenced the mean and standard error (SE) of basal PLT and WBC and the recovery in the L-PRP of the donators. The mean of platelet concentration in L-PRP was $1912 \times 10^{3}$ cells/ $\mu$ l, which represents 7.1 folds higher from the basal number (270.4); The mean of white blood cells in L-PRP was $9.8 \times 10^{3}$ cells $/ \mu 1$, which represents 1.5 folds higher from the basal number (2.3). The mean of red blood cells (RBC) in L-PRP was $0.2289 \times 10^{6}$ cells $/ \mu 1 \mathrm{SE} \pm 0.026$

Preparation of autologous thrombin depends on the method and on inter-individual variability

In order to assess the amount of thrombin in the different types of preparations, all analyses were performed in the same individual sample for serum, L-PRP and T-PRP. No statistically significant difference was observed $(\mathrm{p}=0.4363)$ between different preparations, and the mean thrombin concentrations were $8.63 \mathrm{nM}$ in L-PRP, 8.13 $\mathrm{nM}$ in serum and $7.56 \mathrm{nM}$ in T-PRP (Figure 2A). The coefficient of variation $(\mathrm{CV} \%)$ of thrombin level for L-PRP, serum and T-PRP were $43.0 \%, 35.07 \%, 58.24 \%$, respectively. The serum samples showed a lower CV \% when compared to other methods
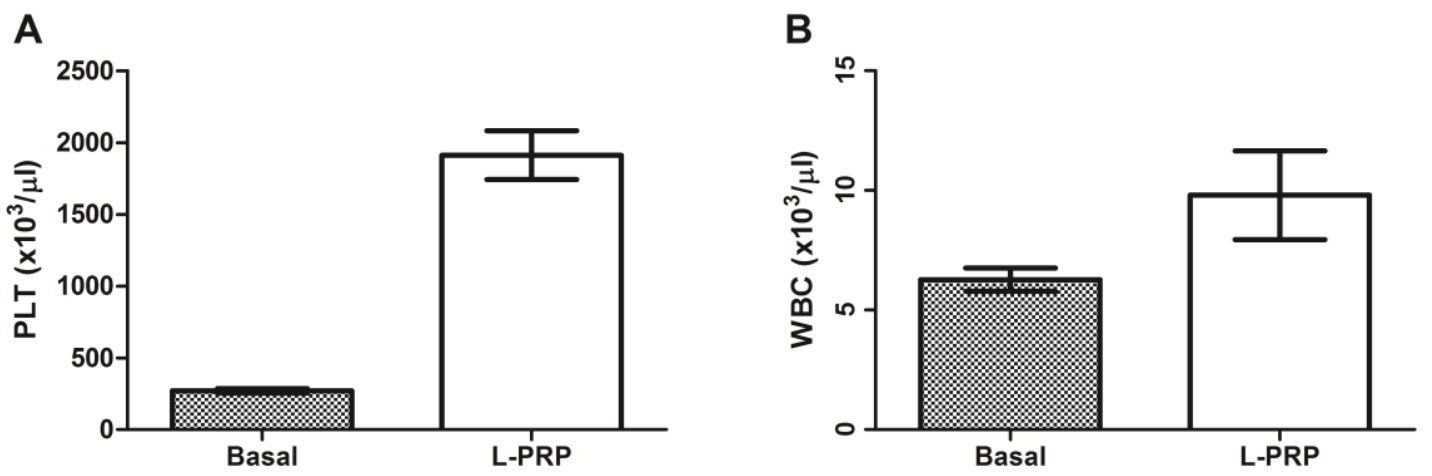

Figure 1: Graphic showing the platelet number of basal and L-PRP (A) and recovery of white blood cells in L-PRP relative to basal number (B), $N=9$

A

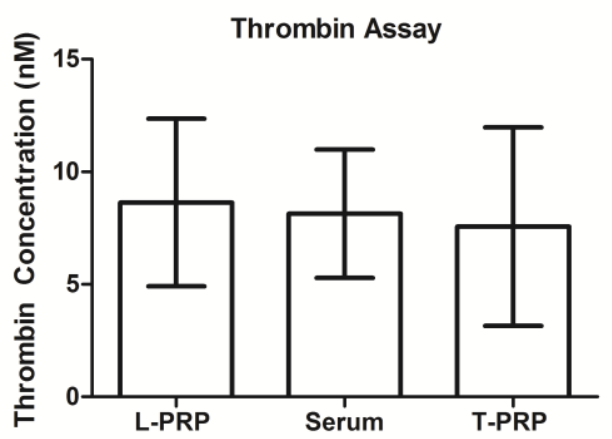

B

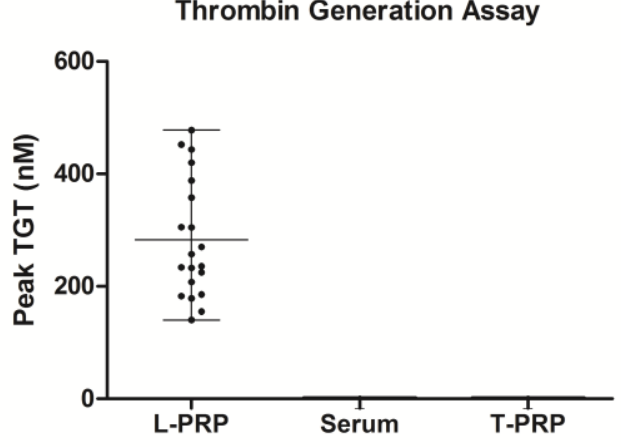

Figure 2: Graphic showing mean of thrombin concentration $(A)$ and peak of thrombin generation by flurogenic assay in PRP, Serum and T-PRP among 20 healthy individuals (B). Mean concentration of thrombin $8.63 \pm 3.73 \mathrm{nM}$ in $\mathrm{L}-\mathrm{PRP}, 8.13 \pm 2.85 \mathrm{nM}$ in serum and $7.56 \pm 4.40 \mathrm{nM}$ in T-PRP 
A

Thrombin Assay

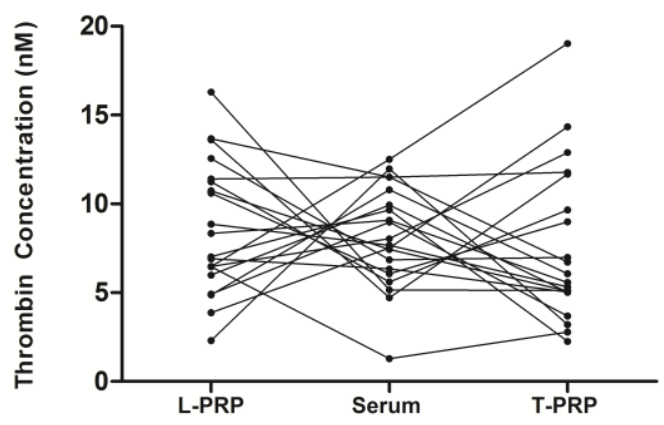

B

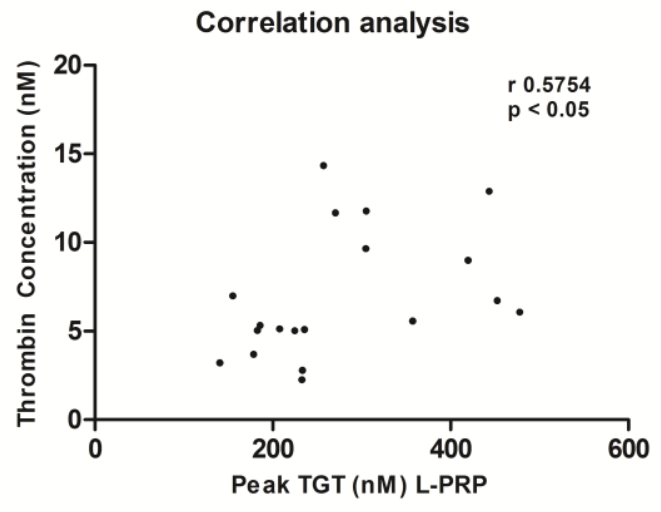

Figure 3: Graphic showing the inter and intra individual variation of thrombin levels in plasma and serum from 20 healthy individuals (A) and showing a significant correlation between thrombin concentration in L-PRP and peak of thrombin generation by thrombin generation test $(T G T)(B), r=0.5754 p<0.05$

Despite of the similar results between the mean of thrombin, no intraindividual trend line was observed, i.e. individuals with high amounts of thrombin in PRP did not show higher amounts of thrombin in TPRP or serum. The intra-individual CV varied from 1.62 to $91.68 \%$ (Figure 3A).

As expected, the TGT test revealed the presence of thrombin precursors only in the L-PRP samples (Figure 2B). TGT results observed in L-PRP presented a statistically significant correlation with the thrombin concentrations measured in L-PRP samples $(\mathrm{r}=0.575, \mathrm{p}<0.05)$ as demonstrated in Figure 3B.

Serum and T-PRP presented a similar period required for PRP gel formation

The time required for L-PRP fibrin formation varied from 1.5 to approximately 22 minutes, except for serum alone and calcium chloride $2.5 \%$ which did not promote fibrin clot. T-PRP showed significantly shorter time when compared to all uses of calcium alone (calcium chloride / gluconate) $(\mathrm{p}<0.05)$, as evidenced in Figure 4. Serum used in association of $0.5 \%$ calcium chloride $(\mathrm{CaCl} 2)$ or $0.5 \%$ gluconate showed significantly shorter time in relation of calcium gluconate $0.5 \%\left(\mathrm{C}_{12} \mathrm{H}_{22} \mathrm{CaO}_{14}\right)(\mathrm{p}<0.05)$ (Figure 4).

The means ( \pm Standard Deviation) of the time (in minutes) for fibrin formation of all activators were: T-PRP: $1.52 \pm 0.45$, Serum $+0.5 \%$ Calcium Gluconate $\left(\mathrm{C}_{12} \mathrm{H}_{22} \mathrm{CaO}_{14}\right): 7.98 \pm 4.91$, Serum $+0.5 \%$ Calcium Chloride $(\mathrm{CaCl} 2): 7.49 \pm 3.38$, Calcium Chloride $0.5 \%$ $(\mathrm{CaCl} 2): 13.92 \pm 3.02$, Calcium Gluconate $0.5 \%\left(\mathrm{C}_{12} \mathrm{H}_{22} \mathrm{CaO}_{14}\right)$ : $22.01 \pm 7.00$, Calcium Gluconate $2.5 \%\left(\mathrm{C}_{12} \mathrm{H}_{22} \mathrm{CaO}_{14}\right): 15.42 \pm 4.02$, as showed in Figure 4.

In order to standardize the procedure above, the thrombin concentrations were evaluated in all nine individuals that were used in this experiment. The mean and coefficient of variation of thrombin concentration in serum and T-PRP were $6.1 \mathrm{nM}(\mathrm{CV} \%$ 46.5) and 4.8 $\mathrm{nM}(\mathrm{CV} \%$ 69.4), respectively.

Growth factor release did not vary according to different thrombin concentrations

Three thrombin concentrations $(2.66,8$ and $24 \mathrm{nM})$ were evaluated for promoting platelet activation and PDGF-AA, EGF and VEGF release. The aim was to identify a correlation between thrombin levels and growth factor release. For this experiment 9 L-PRP were prepared from different healthy individuals, and the platelet number was standardized to $1200 \times 10^{3}$ platelets/ $\mu 1$. No difference was observed between protocols 1 (with nitrogen cycles) and 2 (centrifugation) in the release of growth factors according different thrombin concentrations, as evidenced in the Figure 5 (A and B).

The mean and standard deviation for level of growth factors released in protocol 1 were: EGF $599.3 \mathrm{pg} / \mathrm{mL} \pm 241.9$ for $0 \mathrm{nM}, 504.3$ $\mathrm{pg} / \mathrm{mL} \pm 247.3$ for $2.66 \mathrm{nM}, 519.4 \mathrm{pg} / \mathrm{mL} \pm 202.9$ for $8 \mathrm{nM}$ and $538.8 \mathrm{pg} / \mathrm{mL} \pm 208.2$ for $24 \mathrm{nM}$. VEGF $1426 \mathrm{pg} / \mathrm{mL} \pm 1711$ for 0 $\mathrm{nM}, 1840 \mathrm{pg} / \mathrm{mL} \pm 2379$ for $2.66,1328 \mathrm{pg} / \mathrm{mL} \pm 1715$ for $8 \mathrm{nM}$ and $1136 \mathrm{pg} / \mathrm{mL} \pm 1295$ for $24 \mathrm{nM}$. PDGF-AA $126789 \mathrm{pg} / \mathrm{mL} \pm 219745$ for $0 \mathrm{nM}, 43122 \mathrm{pg} / \mathrm{mL} \pm 22307$ for $2.66 \mathrm{nM}, 43820 \mathrm{pg} / \mathrm{mL} \pm 16927$ for $8 \mathrm{nM}, 40531 \mathrm{pg} / \mathrm{mL} \pm 10676$ for $24 \mathrm{nM}$.

For the protocol 2 (with centrifugation), the mean and standard deviation for level of growth factors released were: EGF 23258 $\mathrm{pg} / \mathrm{mL} \pm 44544$ for $0 \mathrm{nM}, 104629 \mathrm{pg} / \mathrm{mL} \pm 133511$ for $2.66 \mathrm{nM}$, $41070 \mathrm{pg} / \mathrm{mL} \pm 63675$ for $8 \mathrm{nM}$ and $38075 \mathrm{pg} / \mathrm{mL} \pm 71324$ for 24 nM. VEGF $13492 \mathrm{pg} / \mathrm{mL} \pm 26127$ for $0 \mathrm{nM}, 53950 \mathrm{pg} / \mathrm{mL} \pm 81493$ for $2.66,45926 \mathrm{pg} / \mathrm{mL} \pm 103653$ for $8 \mathrm{nM}$ and $30599 \mathrm{pg} / \mathrm{mL} \pm 61828$ for $24 \mathrm{nM}$. PDGF-AA $32262 \mathrm{pg} / \mathrm{mL} \pm 47399$ for $0 \mathrm{nM}, 36343 \mathrm{pg} / \mathrm{mL}$ \pm 16821 for $2.66 \mathrm{nM}, 23028 \mathrm{pg} / \mathrm{mL} \pm 22064$ for $8 \mathrm{nM}, 19046 \mathrm{pg} / \mathrm{mL}$ \pm 16676 for $24 \mathrm{nM}$.

It was observed that the concentrations of growth factors released using the protocol 2 (centrifugation) presents, in general, higher values compared with the release promoted by protocol 1 (nitrogen cycles). This difference was significant only in EGF values in the concentration of 2.66 and $8 \mathrm{nM}(\mathrm{p}<0.0001)$.

As shown in Figure 5, for all thrombin concentrations and protocols used, the levels of growth factors released were similar, evidencing that the concentration of thrombin did not interfere with the release of growth factors in the protocols tested by this study $(\mathrm{p}>0.05)$.

\section{Discussion}

In this study, we evaluated the influence of thrombin in PRP 


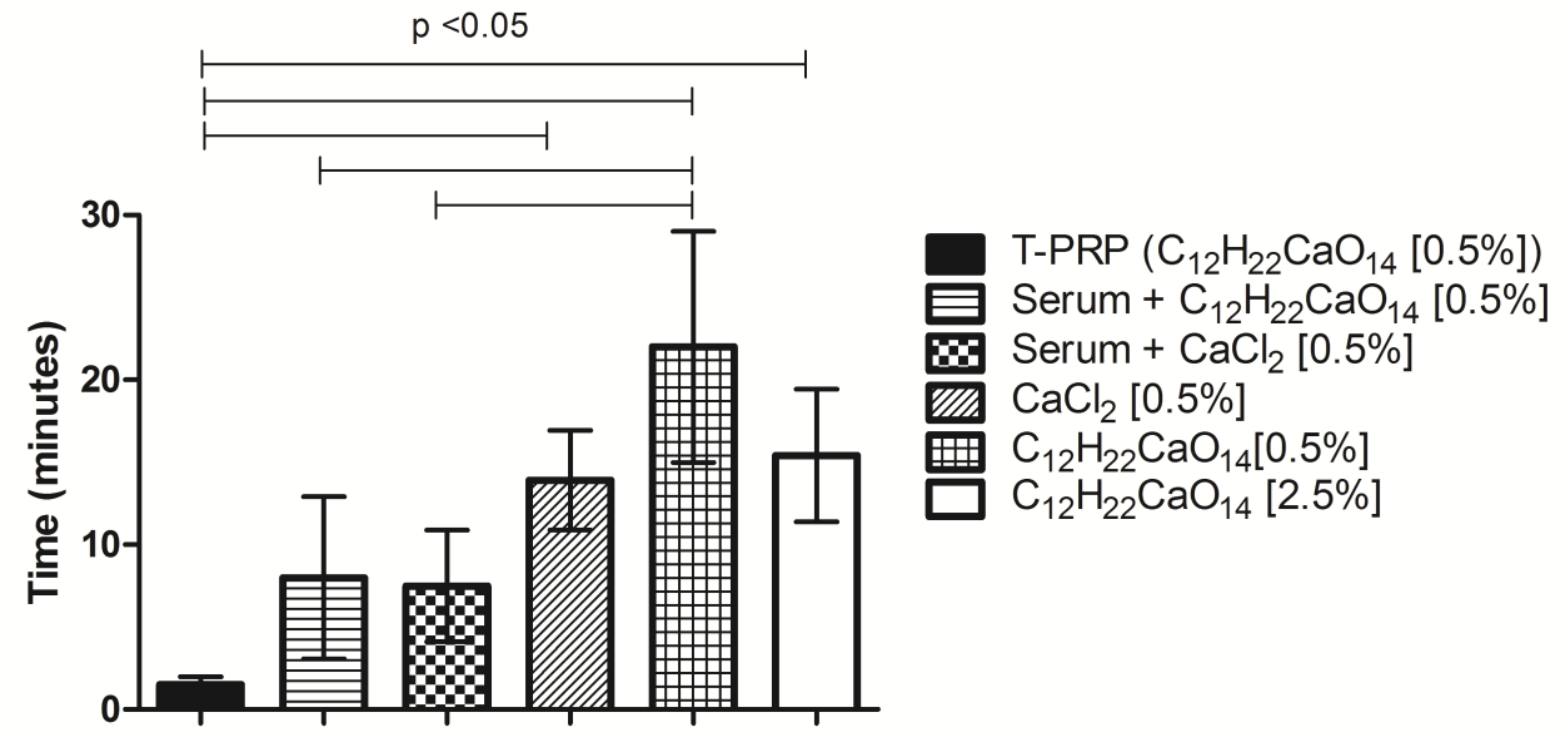

Figure 4: Graphic showing the mean time that different activators took to form the fibrin clot. The use of serum alone and calcium chloride [2.5\%] did not induce clot formation until 30 minutes tested; $N=9$
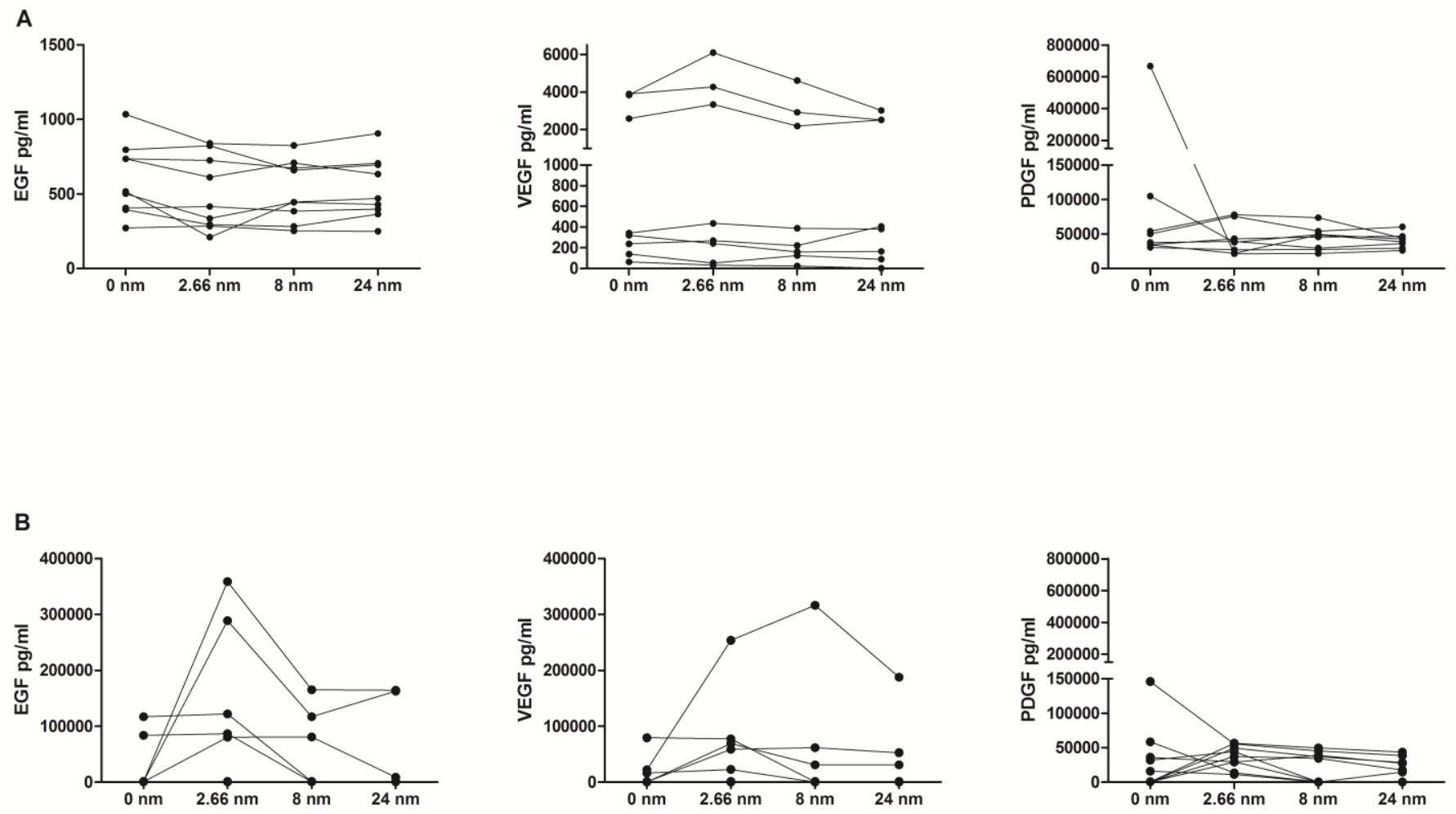

Figure 5: Graphic showing levels of growth factors measured in L-PRP normalized to $1200 \times 10^{3}$ platelets/ $\mu$ l through Multiplex assay according different concentrations of thrombin. A) Protocol 1, using nitrogen cycles; B) Protocol 2, using centrifugation. $p>0.05$ in all analysis. 
preparations. The main aspects investigated were the time for gel formation and the growth factor release. The levels of autologous thrombin were first assessed in serum, L-PRP and T-PRP in the same individual sample, in order to compare and identify the highest thrombin level. Thrombin levels were also evaluated in serum, as this could represent a simple and easy autologous thrombin source. L-PRP was used as basal sample. Unexpectedly, we demonstrated similar levels of thrombin in all preparations. It is well known that thrombin is consumed during fibrin clot formation, and we hypothesized that no thrombin would be present in the serum samples. Our results probably presented residual thrombin formed during serum preparation. In vitro residual thrombin had previously been described by Weiner in an assay to evaluate indirect antithrombin activity in serum samples ${ }^{[21]}$. Otherwise, we also did not expect to detect thrombin in L-PRP, as these samples were anticoagulated. These results are probably due to pre-analytical variables that promote tissue factor release and the activation of coagulation before ACD is mixed to the blood.

An interesting analysis was the capacity of thrombin generation evaluated in L-PRP, serum and T-PRP samples. As expected, precursor thrombin proteins were present only in L-PRP samples. This confirms that all autologous thrombin measured in the serum and T-PRP samples were residual, resulting from the manipulation of the samples. Furthermore, L-PRP thrombin concentration showed a correlation with precursor thrombin proteins levels demonstrated by TGT, this means that when the detection of residual thrombin was high, higher was the capacity of thrombin generation.

Despite the similar mean of thrombin level between serum, T-PRP and L-PRP, a high inter and intra individual variability was observed. Serum presented the lowest inter individual CV. This variability may interfere in clinical practice and is in accordance with our experience, as we have observed a large difference in the period required for platelet gel formation between individual samples. Jo and collaborators showed a similar period required for platelet gel formation with calcium gluconate used singly ${ }^{[22]}$. Our results evidenced that a synergism of thrombin and calcium ions is needed to obtain platelet gel in a short period of time. When each one was evaluated individually, clotting time with calcium alone was close to four folds higher and with serum alone, there was no gel formation.

Regarding this difference in the time required for platelet gel formation, we hypothesized that thrombin levels could interfere in this process and in the release of growth factors from platelets. For this reason, growth factor release was studied for different thrombin concentrations. There is no discussion in the literature regarding the minimum autologous thrombin levels required for the PRP growth factor release. Unexpectedly, we demonstrated through our experiments that the release of growth factors did not increase with higher thrombin concentrations. Actually, we showed that higher concentrations of thrombin yielded a more consistent clot, which was difficult to dissolve with nitrogen.

The use of serum as a source of autologous thrombin achieved good results in growth factor release and in promoting gel formation. In addition, the use of serum samples to obtain autologous thrombin introduces some practical benefits, as no laboratory treatment was required, thus consuming less preparation time, and presenting higher reproducibility. Indeed, according to our results, PRP used as a suspension requires no activation as the levels of growth factor release were similar in both activated and non-activated samples. Probably in this situation, the application of PRP in vivo would be activated when exposed to collagen, elastin, and other proteins.

Amable and collaborators used a mathematical formula to evaluate thrombin levels in $1 \times 10^{6}$ platelet concentration, in order to compare the results with other studies. In their study, PRP was activated with $9 \mathrm{nM}$ of thrombin after an incubation of 16 hours $^{[10]}$. The levels of growth factors released were close to $8500 \mathrm{pg} / \mathrm{ml}$ of PDGF-AA and $500 \mathrm{pg} / \mathrm{ml}$ of EGF. When these levels were compared with our results we demonstrated that EGF levels were very similar (mean of $519.4 \pm 202.9 \mathrm{pg} / \mathrm{ml}$ ) when using the same thrombin concentration, however, the PDGF-AA levels were much higher in our study $(43820 \pm 16927)$ using the protocol 1 . In order to evaluate if the protocols may change the levels of growth factors release, we performed the protocol 2 without nitrogen cycles, and the results were even higher. We believe that the all the procedures to evaluate the release of growth factors have some technical limitations which lead to a variability of the results.

Anitua et al., described the kinetics of growth factor release in platelet clots rich in growth factors (PRGF) activated with $10 \%$ $\mathrm{CaCl}_{2}$ up to 8 days of incubation, and in L-PRP after 24 hours of activation ${ }^{[23]}$. The clots were evaluated with scanning electron microscopy (SEM) in order to evaluate fibrin formation. The weakness of this study is the small number of samples $(n=3)$ and the presentation of the data, in percentage or log, which does not enable comparison with other studies. In 2015, Anitua et al., published another study evaluating the kinetics of other growth factors release (PDGF-AB, transforming growth factor (TGF- $\beta 1$ ), VEGF, hepatocyte growth factor (HGF), insulin-like growth factor (IGF-I), EGF) and interleukins (IL-1 $\beta$ and IL-16) in PRGF and L-PRP clots from 3 donators activated with CaCL2 during 8 days ${ }^{[24]}$. When compared to our results we found a similar result regarding VEGF, during the first hour, however, the EGF levels were higher in our study (mean of $599 \mathrm{pg} / \mathrm{ml}$ - not treated). These high levels could be attributed to the difference in activation (calcium and thrombin) and the nitrogen cycles, used to dissolve the clot and release all the growth factor inside the clot, therefore increasing the concentrations. As expected, pro-inflammatory cytokines were significantly higher in L- PRP during all the period of in vitro experiment (8 days).

Martineau et al., also studied the kinetics of growth factors release (VEGF, PDGF-BB, TGF- $\beta 1$ ) according to different concentrations of thrombin and calcium, and demonstrated similar results when compared to our experiments ${ }^{[25]}$. Indeed, as we observed in our study, VEGF and EGF did not have a significant increase in the release regarding the concentration of activators.

Finally, a practical result of our study was showing the advantages in using serum with calcium instead of T-PRP to activate platelets for gel formation, as this is an easy, quick, low cost and reproducible method, with no laboratory handling and no consuming of PRP. According to our study, no thrombin activation is required for platelet suspension, as the release of the growth factors PDGFAA, EGF and VEGF is the same with and without the presence of thrombin.

\section{Conclusion}

Residual levels of thrombin were detected in serum, T-PRP and autologous thrombin preparations. Serum proved to be the most reproducible technique to activate PRP for gel formation and presented some advantages when compared to other activation methods, such as the easier and faster preparation and the lack of necessity of using part of PRP. Therefore, autologous thrombin can conveniently be prepared from serum samples and be useful for gel preparation. However, the activation with different thrombin concentrations does not show a correlation with release of the growth factors PDGF-AA, VEGF and VEGF, suggesting that no activation is required when using a platelet suspension. 


\section{References}

1. Marx RE. Platelet-rich plasma: evidence to support its use. J Oral Maxillofac Surg. 2004;62(4):489-96.

2. Andia I, Abate M. Platelet-rich plasma: underlying biology and clinical correlates. Regen Med. 2013;8(5):645-58.

3. Arnoczky SP, Sheibani-Rad S. The basic science of platelet-rich plasma (PRP): what clinicians need to know. Sports Med Arthrosc. 2013;21(4):180-5.

4. Albanese A, Licata ME, Polizzi B, Campisi G. Plateletrich plasma (PRP) in dental and oral surgery: from the wound healing to bone regeneration. Immun Ageing. 2013;10(1):23.

5. Cervelli V, Bocchini I, Di Pasquali C, De Angelis B, Cervelli G, Curcio CB, Orlandi A, Scioli MG, Tati E, Delogu P, Gentile P. P.R.L. platelet rich lipotransfert: our experience and current state of art in the combined use of fat and PRP. Biomed Res Int. 2013;2013:434191.

6. Scarpone M, Rabago D, Snell E, Demeo P, Ruppert K, Pritchard P, Arbogast G, Wilson JJ, Balzano JF. Effectiveness of Platelet-rich Plasma Injection for Rotator Cuff Tendinopathy: A Prospective Open-label Study. Glob Adv Health Med. 2013;2(2):26-31..

7. Carter MJ, Fylling CP, Parnell LK. Use of platelet rich plasma gel on wound healing: a systematic review and meta-analysis. Eplasty. 2011;11:e38.

8. Cervelli V, Garcovich S, Bielli A, Cervelli G, Curcio BC, Scioli MG, Orlandi A, Gentile P. The effect of autologous activated platelet rich plasma (AA-PRP) injection on pattern hair loss: clinical and histomorphometric evaluation. Biomed Res Int. 2014;2014:760709.

9. Kutlu B, Aydin RST, Akman AC, Gumusderelioglu M, Nohutcu RM. Platelet-rich plasma-loaded chitosan scaffolds: preparation and growth factor release kinetics. J Biomed Mater Res B Appl Biomater. 2013;101(1):28-35.

10. Amable PR, Carias RB, Teixeira MV, da Cruz Pacheco I, Corrêa do Amaral RJ, Granjeiro JM, Borojevic R. Platelet-rich plasma preparation for regenerative medicine: optimization and quantification of cytokines and growth factors. Stem Cell Res Ther. 2013;4(3):67.

11. Perez AG, Lana JF, Rodrigues AA, Luzo AC, Belangero WD, Santana MH. Relevant aspects of centrifugation step in the preparation of platelet-rich plasma. ISRN Hematol. 2014; 2014: 176060.

12. Brass LF. Thrombin and platelet activation. Chest. 2003;124(3 Suppl):18S-25S.

\footnotetext{
Abbreviations

PRP : Platelet Rich Plasma

L-PRP : Platelet Rich Plasma enriched with Leukocytes

T-PRP : Thrombin produced through Platelet Rich Plasma

PDGF : Platelet Derived Growth Factor

VEGF : Vascular Endothelial Growth Factor

EGF : Epidermal Growth Factor

CV : Coefficient of Variation

SD : Standard Deviation

ACD : Acid Citrate Dextrose anticoagulant

PPP : Platelet Poor Plasma

CAT : Calibrated Automated Thrombin

PLT : Platelets

WBC : White Blood Cells

TGT : Thrombin Generation Test

PRGF : Platelet Clot Rich in Growth Factors

$\mathrm{CaCl} 2$ : Calcium Chloride

SEM : Scanning Electron Microscopy

TGF- $\beta 1$ : Transforming Growth Factor

HGF : Hepatocyte Growth Factor

IGF : Insulin-like Growth Factor
}

13. Park HB,Yang JH and Chung KW. Characterization of the cytokine profile of platelet rich plasma (PRP) and PRP-induced cell proliferation and migration: Upregulation of matrix metalloproteinase-1 and -9 un HaCat cells. Korean J Hematol. 2011;46(4):265-73.

14. Liao HT, Marra KG, Rubin JP. Application of plateletrich plasma and platelet-rich fibrin in fat grafting: basic science and literature review. Tissue Eng Part B Rev. 2014;20(4):267-76.

15. Senzel L, Gnatenko DV, Bahou WF. The platelet proteome. Curr Opin Hematol. 2009;16(5):329-33.

16. Franco D, Franco T, Schettino AM, Filho JM, Vendramin FS. Protocol for obtaining platelet-rich plasma (PRP), platelet-poor plasma (PPP), and thrombin for autologous use. Aesthetic Plast Surg. 2012;36(5):1254-9.

17. Kitchen S, McCraw A, Echenagucia M. Diagnosis of Hemophilia and other bleeding disorders - A laboratory manual. World Federation of Hemophilia 2010; $2^{\circ}$ ed: 1 144.

18. Clinical and Laboratory Standards Institute (CLSI) guideline. One-stage prothrombin time (PT) test and activated partial thromboplastin time (APTT) test; approved guideline H47-HA2 2008; 28(20).

19. Saxena S, Jain P, Shukla J. Preparation of two component Fibrin Glue and its clinical evaluation in skin grafts and flaps. Indian J Plast Surg 2003;36 (1):14-7.

20. Matsui M, Tabata Y. Enhanced angiogenesis by multiple relase of platelet-rich plasma contents and basic fibroblats growth factor from gelatin hydrogels. Acta Biomater. 2012;8(5):1792-801.

21. Weiner M. Residual serum thrombin activity. Clin Chem. 1958;4(4):271-7.

22. Jo CH, Roh YH, Kim JE, Shin S, Yoon KS. Optimizing platelet-rich plasma gel formation by varying time and gravitational forces during centrifugation. J Oral Implantol. 2013;39(5):525-32.

23. Anitua E, Zalduendo MM, Alkhraisat MH, Orive G. Release kinetics of platelet-derived and plasma- derived growth factors from autologous plasma tich in growth factors. Ann Anat. 2013;195(5):461-6.

24. Anitua E, Zalduendo MM, Prado R, Alkhraisat H, Orive G. Morphogen and proinflammatory cytokine release kinetics from PRGF-endoret fibrin scaffolds: evaluation of the effect of leukocyte inclusion. J Biomed Mater Res A. 2015;103(3):1011-20.

25. Martineau I, Lacoste E, Gagnon G. Effects of calcium and thrombin on growth factor release from platelet concentrates: Kinetics and regulation of endothelial cell proliferation. Biomaterials. 2004;25(18):4489-502. 
Huber SC, et al. J Stem Cells Regen Med 2016; 12(1)

\section{Potential Conflicts of Interests}

None

\section{Acknowledgements}

The authors would like to thank FAPESP and CNPq for their financial support.

\section{Corresponding Author}

Stephany Cares Huber, Rua Carlos Chagas 480 - Hemocentro de Campinas - Cidade Universitária Zeferino Vaz - Campinas - SP Brazil - CEP 13083-878; Telephone: +55(19)35218755; Email: stephany_huber@yahoo.com.br; Alternative email: ste.crimson@yahoo.com.br 